\title{
La catedral de Granada: arquitectura y simbolismo. En torno al significado del templo siloesco
}

\author{
Victoriano Sainz Gutiérrez \\ Universidad de Sevilla \\ vsainz@us.es
}

RESUMEN: Por lo general, las interpretaciones sobre los significados que encierra la capilla mayor de la catedral de Granada han girado en torno a su carácter funerario. Atendiendo a la condición jerónima de Pedro Ramiro de Alba, el arzobispo granadino que encargó el proyecto a Diego Siloe, este artículo propone una lectura de la misma en clave de eclesiología eucarística que permite articular esos significados en una visión integradora, de la que participan tanto la arquitectura como los elementos litúrgicos y decorativos, singularmente las vidrieras. En este contexto, los escritos de Hernando de Talavera, monje jerónimo y primer arzobispo de Granada, se revelan como una fuente importante y poco atendida por cuantos hasta la fecha se han ocupado de estudiar la catedral.

PALABRAS CLAVE: Catedral de Granada; Diego Siloe; Hernando de Talavera; Pedro Ramiro de Alba; Eclesiología eucarística; Arquitectura renacentista; Vidrieras.

\section{The Cathedral of Granada: Architecture and Symbolism. On the Meaning of the Temple Designed by Siloe}

ABSTRACT: The interpretation on the meanings contained in the main chapel of Granada cathedral have usually revolved around their funerary character. Bearing in mind the Hieronymite condition of Pedro Ramiro de Alba, the Granada archbishop who commissioned the project to Diego Siloe, this article proposes an eucharistic reading of this church in order to articulate those meanings in an integrating vision, that includes both the architecture and the liturgical and decorative elements, specially the stained glass. In this context, the writings of Hernando de Talavera, Hieronymite monk and first archbishop of Granada, are revealed as an important source that has been neglected by those who studied the cathedral until now.

KEYWORDS: Granada Cathedral; Diego Siloe; Hernando de Talavera; Pedro Ramiro de Alba; Eucharistic Ecclesiology; Renaissance Architecture; Stained Glass.

Recibido: 15 de febrero de 2020 / Aceptado: 6 de mayo de 2020.

La catedral de Granada resulta ser un ejemplo señero de la arquitectura renacentista española, entre otros motivos, porque con el proyecto de Diego Siloe vemos aparecer un nuevo tipo de arquitecto, que se concebía a sí mismo conforme al modelo cuatrocentista italiano. La elaboración, según consta en el archivo catedralicio (Rosenthal, 1990: 29-30), de una maqueta del edificio constituye un claro indicio de la adopción, por parte del artista burgalés, de un modo de afrontar el proyecto de arquitectura diverso del medieval, ya claramente perfilado en Italia al menos desde Brunelleschi. El recurso a esa herramienta para expresar la idea proyectual iba a la par con el empleo de las formas «a lo romano» que Siloe tuvo ocasión de conocer durante su estancia en Nápoles, mientras trabajaba en la iglesia de San Giovanni a Carbonara (Toajas, 2007: 10-12).

La capilla mayor de la catedral granadina, en su recurso a la planta central característica de la arquitectura antigua, evidencia sin embargo hasta qué punto Siloe supo servirse libremente de los modelos del pasado, al entenderlos más como experiencia que como principio de autoridad, situándose más allá de cualquier fórmula normativa al mezclar lo clásico con lo gótico. Por eso pudo Gómez-Moreno escribir de él que «es ya un barroco, en el sentido de caldear con genialidades el pa-

Cómo citar este artículo: SAINZ GUTIÉRREZ, Victoriano, «La catedral de Granada: arquitectura y simbolismo. En torno al significado del templo siloesco», Boletín de Arte-UMA, n..$^{41}$, Departamento de Historia del Arte, Universidad de Málaga, 2020, pp. 227-237, ISSN: 0211-8483, e-ISSN: 2695-415X, DOI: http://dx.doi.org/10.24310/ BoLArte.2020.v41i.7886 
trón clásico, de alegrar con golpes de fantasía el trazado arquitectónico sin desvirtuarlo» (1963: 12); se estaba refiriendo con ello, más que a cuestiones estilísticas, al peculiar modo siloesco de afrontar los problemas arquitectónicos, que hizo de él una verdadera «águila» de la arquitectura española (Gómez Moreno, 1941).

Se ha señalado a menudo que la catedral de Granada se halla a medio camino entre tradición e innovación, donde por tradición hay que entender la estructura de nuestras últimas catedrales góticas y por innovación las nuevas formas provenientes de Italia, subrayando que en ella «se mezclan de forma inextricable la continuidad y la ruptura» (Marías, 1988: 118). En esa misma línea, querría mostrar, acudiendo a fuentes hasta ahora poco explotadas, cómo Siloe contribuyó con esta catedral a renovar el significado del espacio sacro. Se hace, pues, necesario comenzar con una breve referencia a la evolución del sentido y la forma del templo cristiano.

\section{El significado del templo cristiano en el tránsito de la Edad Media a la Moderna}

El nacimiento del gótico no puede ser entendido al margen de la decidida apuesta de Bernardo de Claraval por un arte purificado, más acorde con la propia experiencia espiritual, por cuanto, para él, el arte religioso solo se justificaba por su capacidad para conducir la mente a la contemplación de la Verdad última. El primero en afrontar este desafío y resolverlo de un modo verdaderamente nuevo fue Suger de Saint-Denis, quien en la cabecera de su abadía parisina fijó el prototipo de la arquitectura gótica. De la lectura del De consecratione, un opúsculo escrito con motivo de su dedicación como templo cristiano, se desprende que la novedad del gótico estuvo, más que en la invención de unas soluciones técnicas, en el descubrimiento de las posibilidades simbólicas de unas formas ya antes empleadas por la arquitectura normanda.

El templo gótico continuaba siendo una imagen de la ciudad celeste, pero sustituía la representación pictórica del cielo que decoraba el ábside románico por la expresión gráfica del sistema estructural. «Mientras que el pintor románico no podía hacer otra cosa que engañar a los sentidos con la ilusión de la realidad última, el constructor gótico aplicaba las mismísimas leyes que ponen orden en los cielos y en la tierra» (Von Simson, 1980: 59). Y para ello se apoyaba en la función anagógica de la imagen simbólica expresada en el templo: una imagen creada por Suger mediante el equilibrado empleo de la geometría y la luz, las cuales, llevando de lo visible a lo invisible, habían de conducir a la contemplación de la Jerusalén celestial representada en el edificio.

La proporción y la luminosidad, convertidas en claves del simbolismo de la catedral gótica, manifestaban además una determinada concepción del orden, no solo desde el punto de vista arquitectónico, sino también desde el punto de vista social, de modo que, siendo el edificio una representación de la ciudad celeste, servía asimismo de referencia para la sociedad medieval jerárquicamente organizada; de ahí que la catedral gótica pudiera ser descrita como una imagen del cuerpo de Cristo. $Y$ es que, tras las controversias eucarísticas del siglo XI, se había comenzado a aplicar a la Iglesia la denominación corpus mysticum, en lugar de la anterior corpus verum, que a partir de entonces quedaría reservada para la eucaristía'.

Desde el punto de vista urbano, lo más relevante de las catedrales góticas será su imponente presencia física y su capacidad para proyectar sobre el paisaje de la ciudad la imagen de una sociedad cristiana, en la que lo religioso y lo socio-político estaban inextricablemente unidos. Por eso, el templo cristiano, como imagen de Cristo, lo sería también de ese corpus mysticum constituido por los cristianos, los cuales en su variedad de oficios y estamentos aparecían representados en las vidrieras, en una original y sugestiva mezcla de historia de la salvación y realidad cotidiana [1].

Ahora bien, el hecho que de la expresión corpus verum comenzara a aplicarse no ya al cuerpo social, sino al cuerpo sacramental de Cristo, pone de manifiesto transformaciones de una trascendencia que solo el transcurso el tiempo permitirá valorar adecuadamente, pero cuyas raíces han ser rastreadas en aquel cambio lingüístico analizado por Henri de Lubac. Y es que en el tránsito del siglo XII al XIII habría comenzado a producirse un desplazamiento del interés desde lo social a lo individual, que se hará palpable con la devotio moderna, pero que se apuntaba ya en la inversión terminológica corpus verum/corpus mysticum: «Fue entonces cuando tanto los teólogos como los canonistas empezaron a distinguir los dos cuerpos del Señor: uno, el corpus verum individual del altar, la hostia; y el otro, el corpus mysticum colectivo, la Iglesia» (Kantorowicz, 1985: 192). 


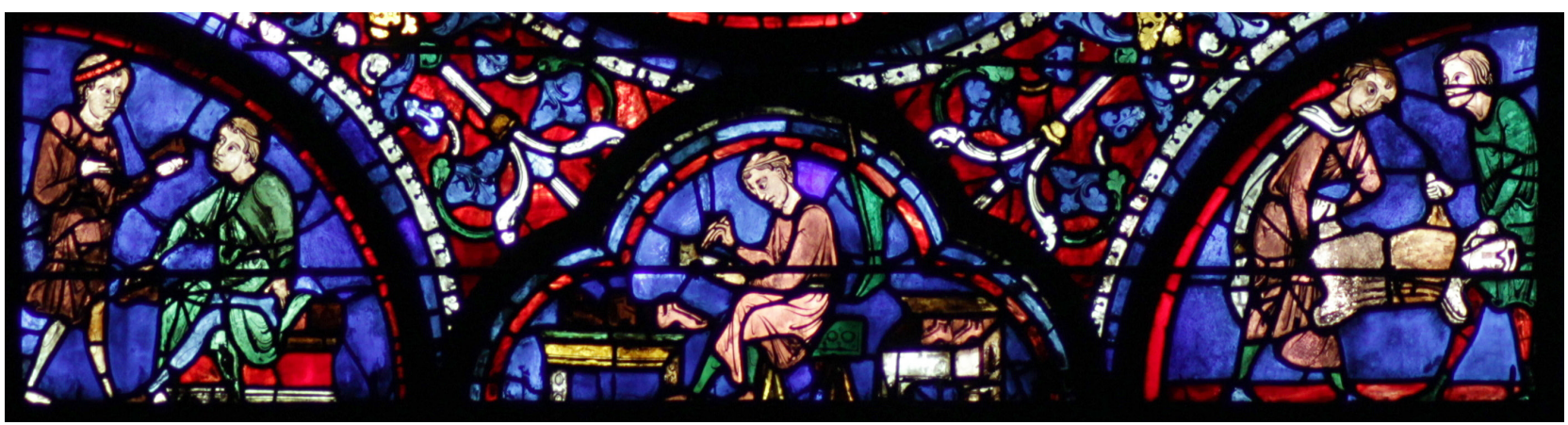

1. Gremio de los zapateros. Detalle de la vidriera de la dormición de la Virgen (1205-15). Fachada sur de la catedral de Chartres

La expresión corpus mysticum aplicada a la Iglesia, que en un primer momento estuvo estrechamente ligada a la eucaristía, no tardó en disociarse de esa realidad sacramental y en quedar reducida al ámbito jurídico, para significar la Iglesia como realidad sociológica corporativa; de ahí que pronto pareciera preferible la expresión corpus Ecclesiae mysticum a la de corpus Christi mysticum. Se estaba significando con ello el paso de la Iglesia concebida como un cuerpo, del que Cristo era la cabeza, a la Iglesia considerada como una persona mística, como un corpus fictum de naturaleza jurídica, cuya cabeza era el romano pontífice.

Este modo de concebir la Iglesia no era ajeno al proceso de secularización que entonces comenzaba a insinuarse y que provocaría una progresiva radicalización de las actitudes en liza, a menudo fuertemente politizadas. Así, mientras por un lado se afirmaba una comprensión netamente institucional de la Iglesia, que ponía el acento en los signos exteriores, los únicos relevantes desde el punto de vista jurídico, por otro cobraba cada vez mayor fuerza una concepción espiritualista de la misma, que se fijaba sobre todo en los aspectos invisibles. Ese enfrentamiento desembocaría en la Reforma luterana, de resultas de la cual -simplificando mucho- los católicos acabarían optando por el corpus verum y los protestantes por el corpus mysticum.

Una aportación española desde la corriente espiritual de los jerónimos

Pero antes de que esa ruptura llegara a formalizarse se dieron otros posicionamientos, que tendrían su importancia también para la evolución de la arquitectura del templo cristiano. En el contexto español tuvo especial relevancia la disputa generada con la aprobación en Toledo de una sentencia, dictada en 1449, que inhabilitaba a los conversos del judaísmo para ocupar cargos públicos, por cuanto iba a marcar decisivamente la historia política y religiosa de las décadas siguientes. El primer alegato contra cualquier distinción entre quienes habían recibido el bautismo vino de la mano de un converso ilustre: el obispo de Burgos, Alonso de Cartagena. En su Defensorium unitatis christianae insistió en la igualdad de todos los cristianos en el interior de una Iglesia cuya única guía era la luz de la fe; asunto este que preside toda su argumentación, convirtiéndose en «la clave de todas sus demostraciones de la unidad del pueblo cristiano» (Pastore, 2010: 45).

Poco después, el monje jerónimo Alonso de Oropesa escribirá su Lumen ad revelationem gentium, un ambicioso tratado redactado a instancias del prior de Guadalupe con la intención de poner fin a las luchas intestinas que enfrentaban a cristianos nuevos y cristianos viejos en el interior de dicho monasterio. $Y$ es que la de los jerónimos fue la orden por excelencia de los judeoconversos, en especial desde que en 1437 manifestara su apertura incondicional a que estos pudieran incorporarse a ella. En el Lumen, Oropesa fomentaba un cristianismo interior y radical, fundamentado en la participación de cada fiel en el único sacrificio de Cristo, a través del cual se llevaba a cabo la unidad de su cuerpo místico: «Todos en común y sin diferencias -escribe- estamos aunados por una caridad inefable en este sacrificio de Cristo, como en un amistoso banquete suavísimo y admirable, por lo que tenemos que ser iguales, unánimes y concordes» (Oropesa, 1979: 371). 


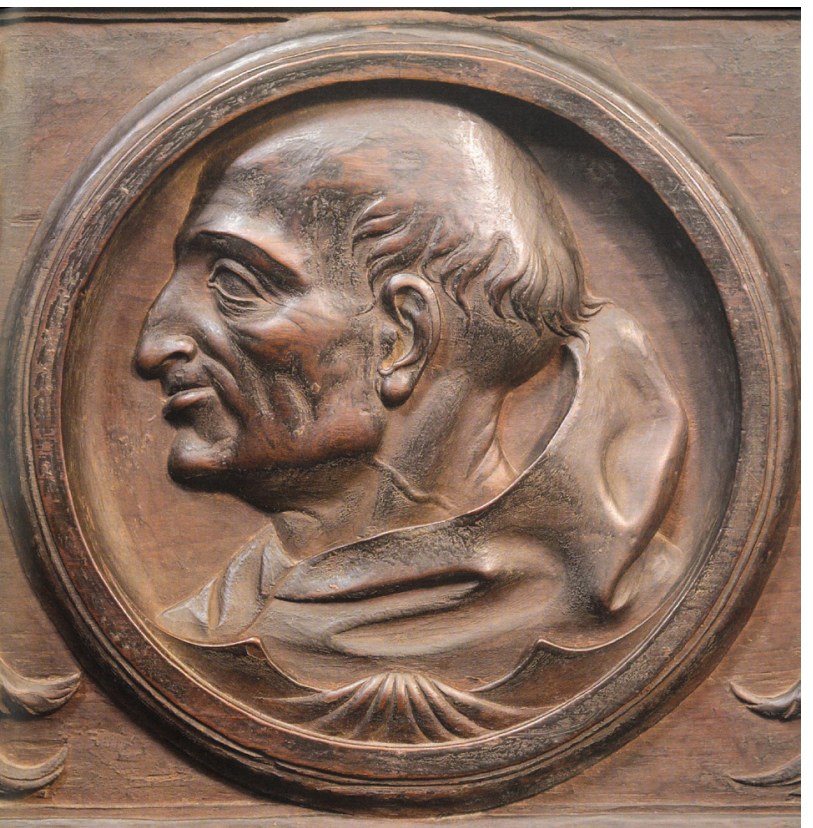

2. Diego Siloe, Fray Hernando de Talavera (1544). Sillería del coro. Monasterio de San Jerónimo, Granada

Para lo que aquí nos interesa el tratado de Oropesa resulta de capital importancia porque es «una de las más esenciales referencias de [la] propuesta religiosa y espiritual» de Hernando de Talavera (Pastore, 2010: 74)², también monje jerónimo y primer arzobispo de Granada [2], quien verterá las reflexiones teológicas del Lumen en un conjunto de consideraciones destinadas a facilitar la participación de los fieles en el sacrificio eucarístico, en especial mediante un Tractado de las cerimonias de la misa donde se propone «compilar brevemente las imaginaciones e pensamientos en que nuestro espíritu se debe ocupar en tanto que la misa se celebra» (Talavera, 1911: 80). La propuesta talaveriana buscaba promover una espiritualidad radicada en la experiencia interior de la fe, en gran medida apoyada en las enseñanzas de san Pablo. De ahí su insistencia en concebir la Iglesia con la imagen del cuerpo místico; una imagen entendida por él en el sentido de que Cristo «ayuntó en un edificio, templo e iglesia, las dos paredes diversas que eran los dos pueblos muy contrarios y muy diversos: gentil conviene a saber, y judiego" (Talavera, 2014: 117-118).

En ese contexto de tensión social y política entre cristianos viejos y cristianos nuevos, Talavera -perteneciente él mismo a una familia de conversos- se remitirá una y otra vez a san Pablo, para quien «ni daña, ni aprovecha ser judío o griego, libre o siervo, macho o hembra, mas ser bautizado, y vestir y seguir las costumbres de Jesucristo, nuestra muy sancta cabeça» (Talavera, 2014: 165). Este planteamiento se vería ampliado a los moriscos durante su etapa granadina, toda vez que Talavera era enemigo de buscar las conversiones forzadas y promovió, de acuerdo con lo estipulado en las capitulaciones de 1491, una participación activa de los recién bautizados en las ceremonias de su nueva religión (Folgado, 2014), cosa no siempre bien vista por otras instancias eclesiásticas castellanas.

La fuente principal de la pastoral emprendida por el arzobispo granadino se hallaba en lo que él consideraba que habían sido las "costumbres apostólicas", inspiradas por la idea que él se había hecho de lo que fue la vida de los primeros cristianos. Por eso, en su testamento espiritual, recogido por sus primeros biógrafos, hizo constar que «su yntençión había sido de reduzir su Yglesia al estado de la primitiva», además de pedir a quienes le siguieran en el gobierno de la diócesis «que trabajasen por llevar adelante todo lo bueno que avía empeçado, y que no solamente lo conservasen, mas creçiesen siempre persiguiendo su yntento ${ }^{3}$.

\section{Siloe y la tradición jerónima}

Cuando Carlos V Ilegó a Granada en 1526 hacía ya casi veinte años del fallecimiento de Talavera, pero su memoria permanecía extraordinariamente viva4. Por entonces las obras para la construcción de la cabecera de la catedral acababan de comenzar, siguiendo la traza gótica dada por Enrique Egas al proyectar la capilla real; en ella fueron enterrados tanto los Reyes Católicos como Felipe el Hermoso, cuyo cadáver había llegado a Granada en 1525, procedente de Tordesillas. Tras visitar este lugar de enterramiento, Carlos V lo consideró oscuro y limitado en su concepción espacial, razón por la cual determinó instalar el panteón imperial en la nueva catedral, manteniendo los restos de sus abuelos y de su padre en el lugar contiguo a esta donde ya reposaban. Esta decisión carolina estaba llamada a tener importantes repercusiones en el replanteamiento del proyecto catedralicio que Siloe llevaría a cabo poco después. 
Todo parece indicar que el arquitecto burgalés recibió en 1528 ese encargo a través del nuevo arzobispo promovido por el emperador durante aquella estancia granadina: el jerónimo Pedro Ramiro de Alba; al menos eso parece deducirse de la documentación disponible, que muestra a Siloe trabajando en esa misma fecha en la iglesia del monasterio de San Jerónimo ${ }^{5}$, del que Alba había sido prior (Marías, 1989: 513). No parece haber acuerdo, en cambio, respecto a quién fuera el promotor de ese cambio de arquitecto -y del consiguiente paso del estilo gótico al «romano»-, si fue el arzobispo o el propio Carlos $\mathrm{V}$, pero en cualquier caso es claro que Siloe respondió al encargo aportando una solución del todo novedosa.

Se ha debatido mucho sobre las fuentes utilizadas por Siloe; vista la ausencia de precedentes en la arquitectura española, estas solo podían ser italianas. Y es indudable que las empleó con una gran libertad para transformar la cabecera gótica proyectada por Egas en una rotonda cupulada apoyada en grandes pilares radiales. Sin duda la referencia al Panteón de Roma, implícita en esta solución, debe relacionarse con el carácter funerario que adquirió el templo, conforme al deseo del emperador (Bustamante y Marías, 1982: 111); no obstante, se ha de tener en cuenta además el deseo de sus abuelos de que los sepulcros reales, siguiendo quizá la antigua tradición del panteón real de León, se colocaran ante el Santísimo ${ }^{6}$. Solo atendiendo a esta estrecha vinculación de los enterramientos regios con el sacramento eucarístico, en el que la liturgia católica vio un anticipo de la vida eterna, se llega a dar con la raíz de la original estructura de la catedral granadina.

No hay duda de que la decisión carolina de situar el panteón imperial en la capilla mayor de la catedral llevó consigo su consideración de monumento funerario, para lo cual resultaba especialmente apta la planta centralizada, que daría a la cabecera un cierto carácter autónomo respecto a las naves de la catedral. Sin embargo, la rotonda y el salón no necesariamente han de ser vistos como dos entidades independientes y de difícil articulación tanto física como simbólica. Determinadas pinturas cuatrocentistas donde el cenáculo de Jerusalén aparece representado como una estancia compuesta por una rotonda y un salón, como La comunión de los apóstoles, de Justo de Gante [3], ayudan a situar la catedral granadina en un contexto eucarístico, sin perder por ello su carácter funerario; más aún, en Granada,

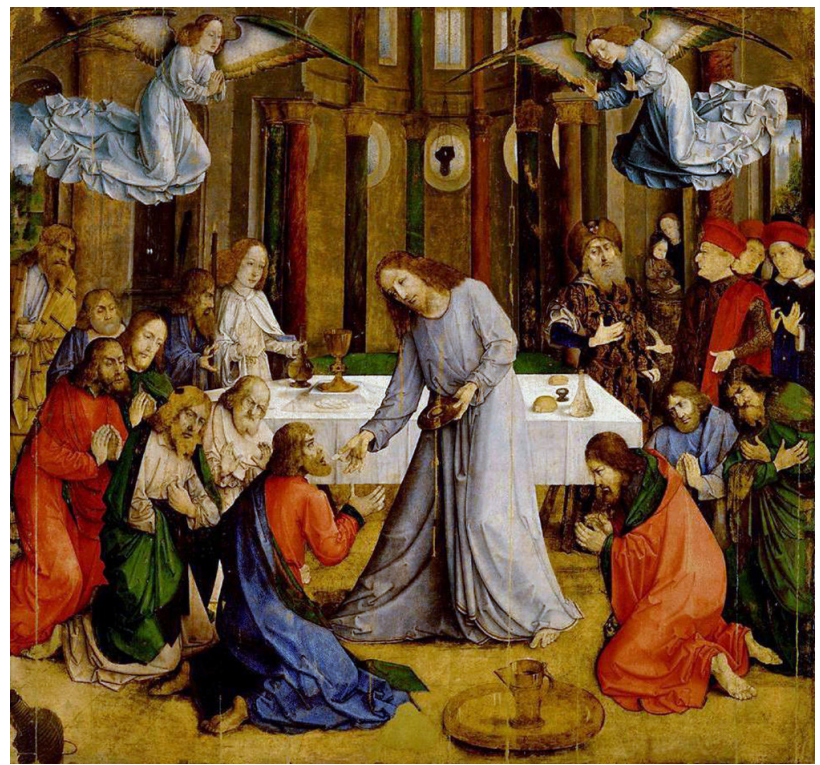

3. Justo de Gante, La comunión de los apóstoles (1473-75 ca.). Galleria Nazionale delle Marche, Urbino

como ya sucedía en León, uno y otro se hallan íntimamente relacionados.

Desde este punto de vista, el altar situado en el centro de la rotonda, para el cual Siloe diseñaría su tabernáculo, se convierte así en una pieza clave, que vertebra todo el universo simbólico construido en torno a ese espacio. Llama por eso la atención que no se le haya prestado más atención al estudiar la catedral granadina y que, cuando se ha hecho en un estudio reciente, a pesar de que se haya señalado acertadamente que "para comprenderlo [...] se ha de tener en cuenta sobre todo la figura de fray Hernando de Talavera» (Peinado, 2010: 44), no se haya profundizado en esa relación del proyecto siloesco con la espiritualidad jerónima, en la que quedó inscrito por quien fuera su comitente, el arzobispo Ramiro de Alba. Es lo que me propongo hacer a continuación, con el fin de aportar nueva luz sobre el significado del templo tal como fue concebido por el maestro burgalés.

También por eso resulta adecuada la expresión «proyecto Alba-Siloe de 1528» utilizada por Rosenthal (2005: 99) para referirse al proyecto renacentista del nuevo templo catedralicio, pues si las innovaciones arquitectónicas son atribuibles al arquitecto, las implicaciones simbólicas y ceremoniales que subyacen a esas nuevas formas solo pueden 


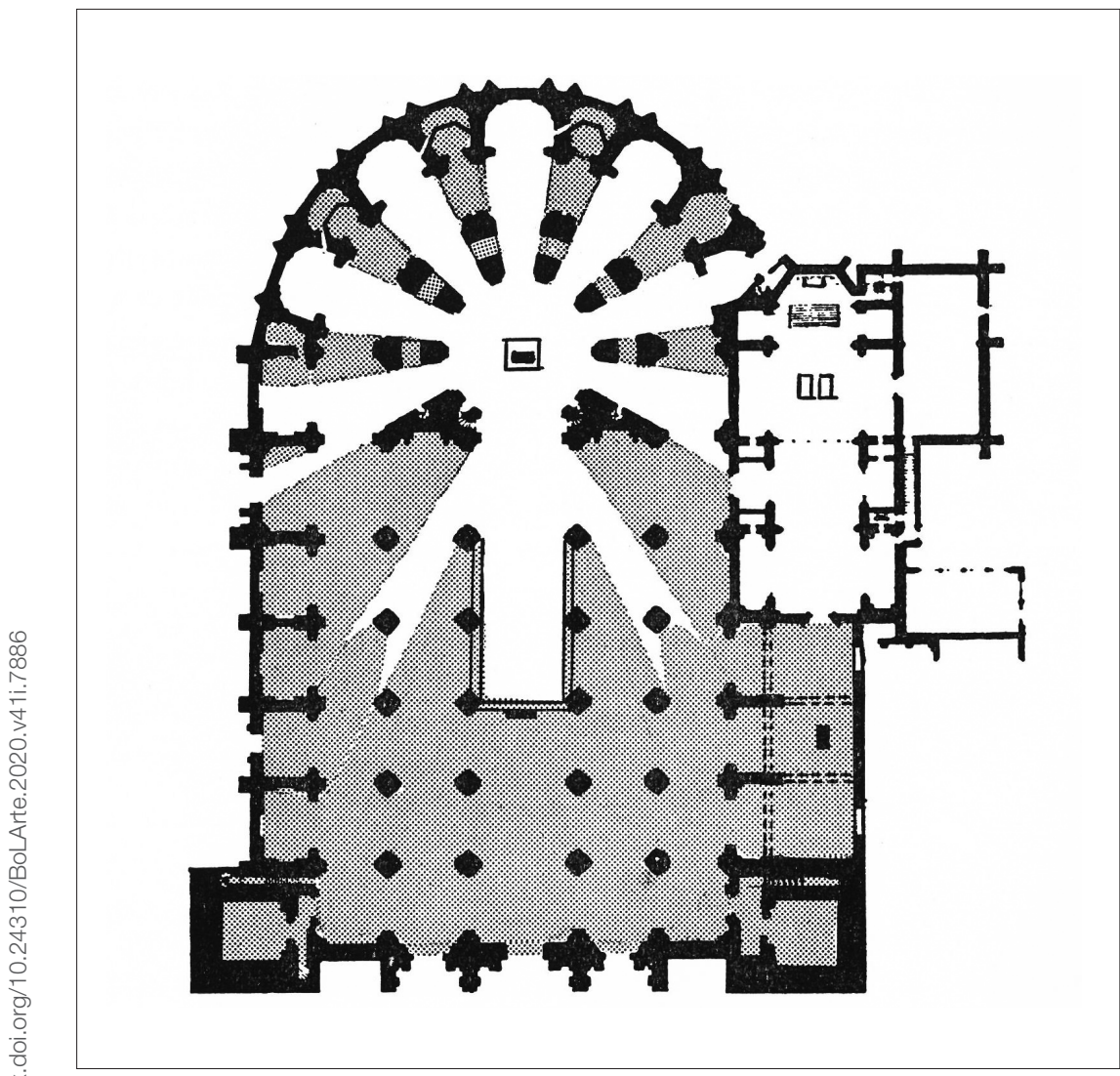

4. Planta de la catedral de Granada mostrando las zonas desde las que es visible el altar mayor. Dibujo de $\mathrm{E}$ Rosenthal (1961)

entenderse desde la tradición jerónima representada por el arzobispo. De hecho, el singular modo en que quedó situado el altar mayor en el centro de la rotonda, de modo que toda la cabecera girase en torno a él, para que pudiese ser visto tanto desde el deambulatorio como desde la corona de capillas radiales [4], remite al significado eclesiológico de la eucaristía, es decir, a la mutua implicación del corpus verum y el corpus mysticum antes mencionada. Esta relación la encontramos explicitada, precisamente a propósito del altar, en el citado Tractado de Talavera, donde se lee que este «representa [...] otrosí el ayuntamiento de los fieles que fueron, son e serán desde el comienzo del mundo hasta la fin; el cual ayuntamiento se llama Iglesia e confradía o hermandad de Jesucristo» (Talavera, 1911: 80). Es, pues, esa eclesiología elaborada por Cartagena y Oropesa, luego hecha propia por Talavera, la que parece subyacer en las formas proyectadas por Siloe, pero para confirmarlo será preciso realizar un examen más detenido del programa iconográfico siloesco.
Una lectura en clave eucarística de las vidrieras de la capilla mayor

La referencia al conjunto de los fieles formando un solo cuerpo con su cabeza constituye de algún modo la clave simbólica del carácter centrípeto de la cabecera de la catedral ${ }^{7}$, que ha sido interpretado como una vuelta al «culto del cristianismo temprano entendido como algo participativo, que incluía e implicaba a la congregación de los fieles» (Rosenthal, 2005: 114). Pues bien, lo más interesante del tratadito de Talavera es que constituye una guía para asegurar la participación activa de los fieles en la misa, permitiendo a quienes viven sus ritos obtener fruto espiritual de ellos. El camino para lograrlo pasa por entender los misterios de la vida de Cristo que se hallan representados en la misa (Talavera, 1911: 80). Y, curiosamente, muchas de las escenas evocadas al respecto en el texto talaveriano coinciden con las que figuran en las vidrieras de la rotonda [5], como si estas tuvieran una función mnemónica. 


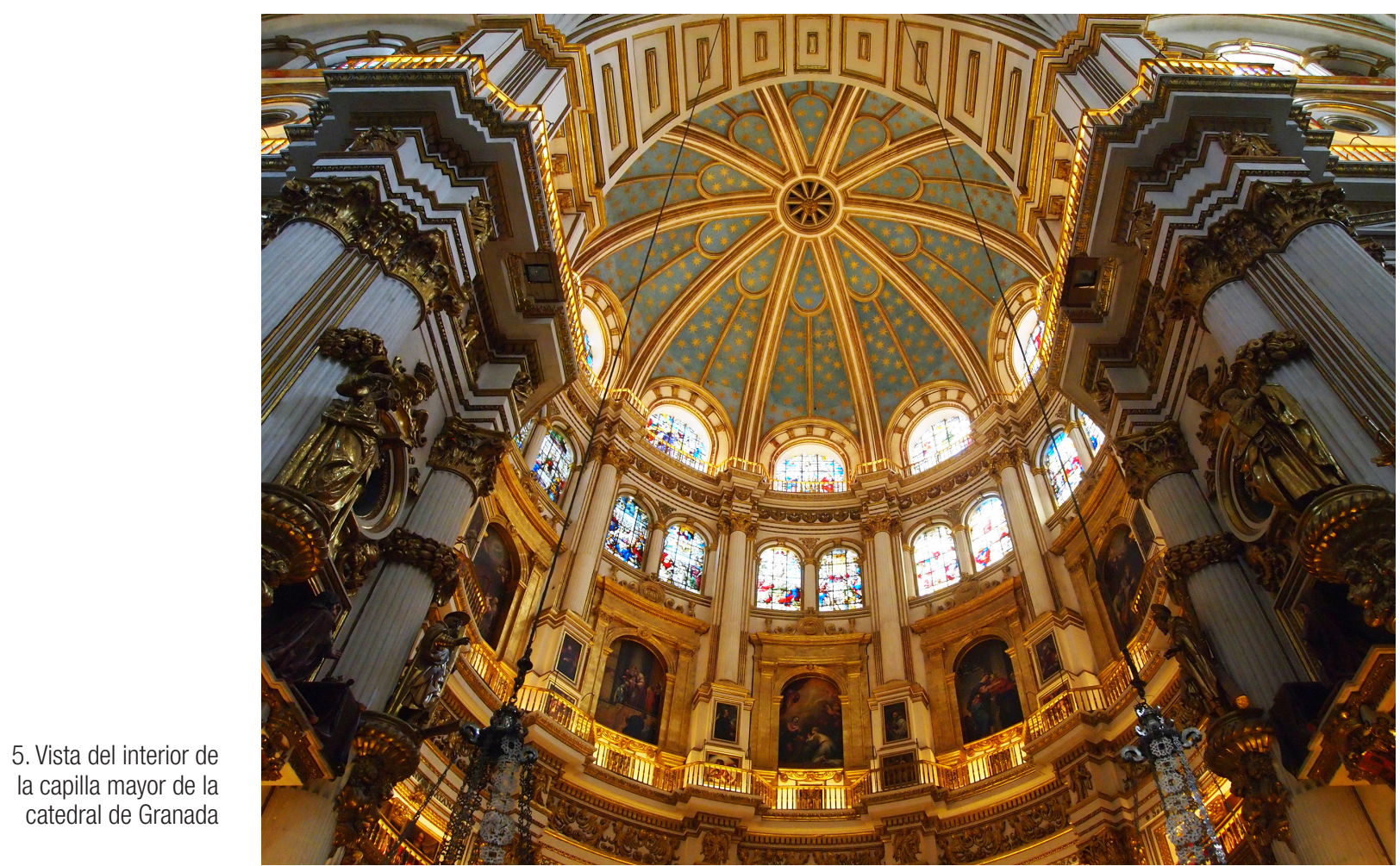

6. Juan del Campo, Cristo con la cruz a cuestas (1559-60). Vidriera de la capilla mayor de la catedral, Granada

Así, entre otras mencionadas por Talavera, el beso del sacerdote al altar significa el amor con que Cristo se abrazó a la columna donde fue azotado (flagelación') y a la cruz que le sirvió de patíbulo (cruz a cuestas) [6]; el saludo Dominus vobiscum que el sacerdote dirige al pueblo representa el de Cristo a sus discípulos después de la resurrección (aparición a la Magdalena); los corporales que se colocan sobre el altar remiten a la sábana en que el cuerpo muerto del Señor fue envuelto (descendimiento de la cruz); y la ofrenda del pan y el vino invita a recordar los dones ofrecidos por los tres reyes magos (epifanía) [7]. Cabría multiplicar las referencias, pero estas ya permiten entender cómo pudieron colaborar Siloe y Alba para la materialización del programa iconográfico del templo ${ }^{9}$, al situar los motivos de las vidrieras en un contexto netamente eucarístico.

Conviene reparar, además, en que todo el ciclo gira en torno al eje definido por las tres ventanas situadas frente al arco de triunfo y la que se halla sobre él, cuyas vidrieras están dedicadas, respectivamente, a los tres aspectos que

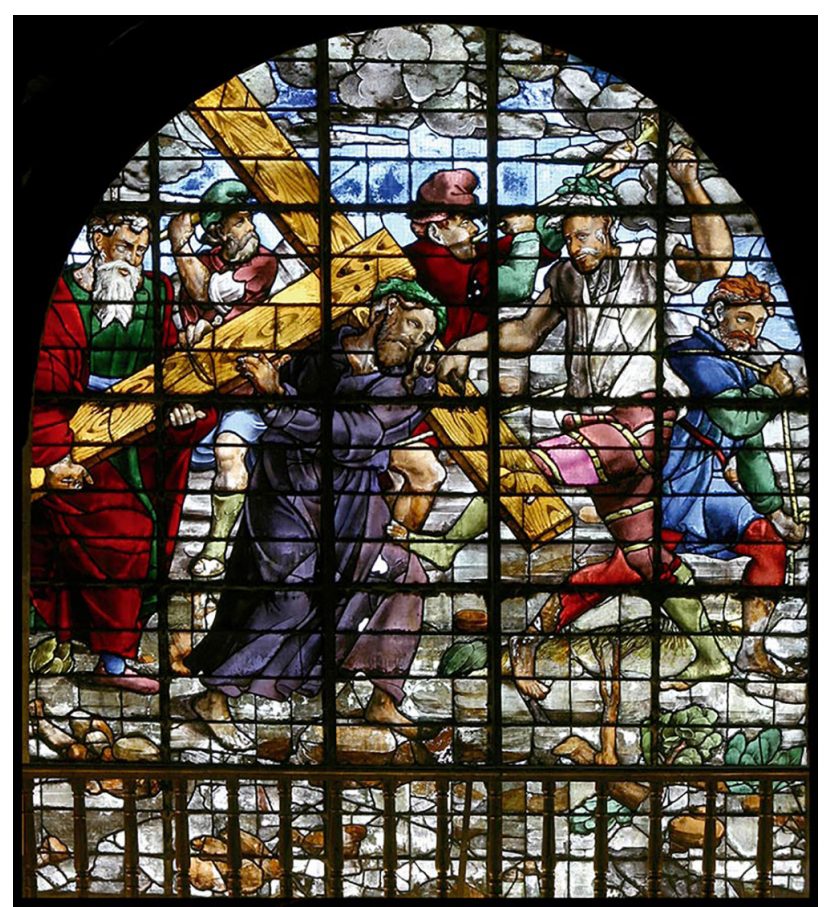




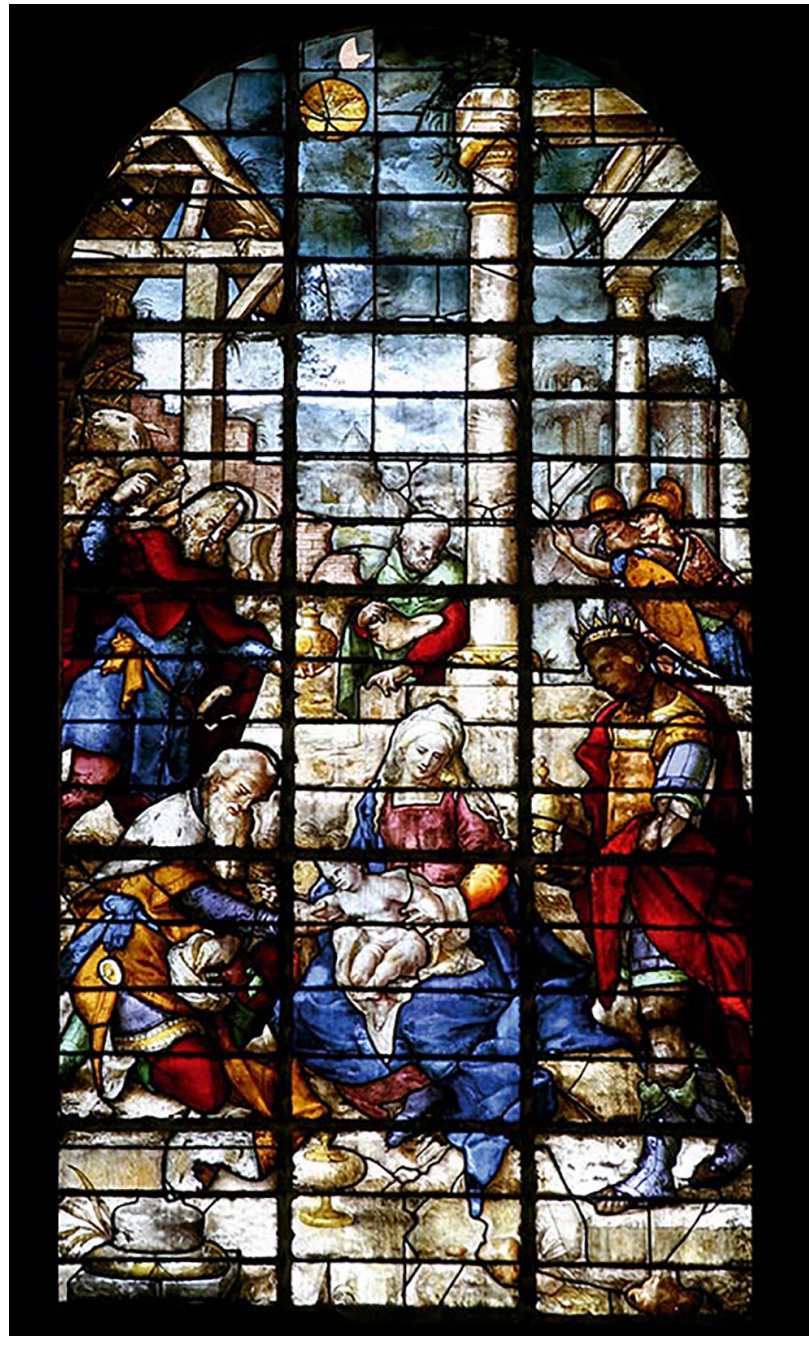

7. Teodoro de Holanda, La epifanía (1559). Vidriera de la capilla mayor de la catedral, Granada

anuda en sí el misterio eucarístico: el sacrificio (crucifixión) [8], el sacramento (última cena) [9] y la presencia (transfiguración), y al Espíritu Santo como quien hace posible la perpetuación de ese misterio en la Iglesia (pentecostés). Son, pues, estas vidrieras las que no solo dotan a la serie de «gran homogeneidad y unidad temática» (Nieto, 1973: 16), sino las que de algún modo vinculan todo el ciclo al significado general del edificio.

A este respecto diversos autores han visto en el hecho de que, en el altar mayor de la catedral granadina, el sacerdote celebrase frente al pueblo, o rodeado por él, un retorno a la praxis litúrgica de aquellos tiempos apostólicos a los que

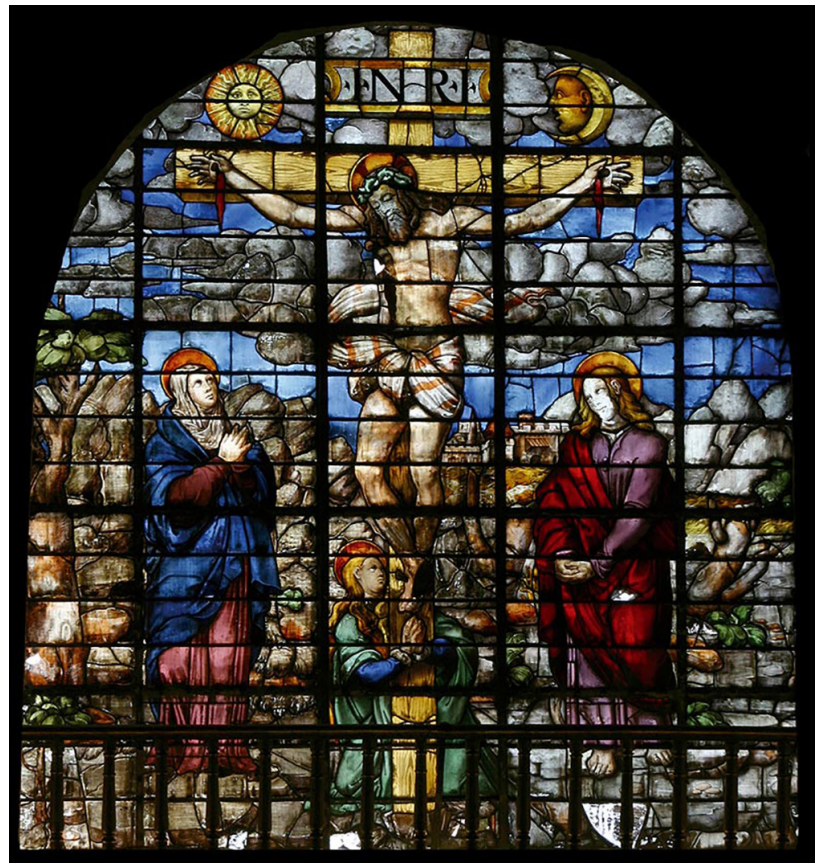

8. Juan del Campo, La crucifixión (1559-60). Vidriera de la capilla mayor de la catedral, Granada

Talavera deseaba volver ${ }^{10}$. Es posible que así fuese; sin embargo, parece más probable que esa disposición ceremonial estuviera ligada sobre todo a la praxis, habitual durante mucho tiempo en ese altar, de tener expuesto el Santísimo, para lo cual Siloe diseñó el ciborio que aparece en el grabado de Heylan (López, 2000: 129), en el cual se puede ver también una custodia eucarística colocada sobre el altar [10]. Henríquez de Jorquera dejó constancia del

[...] curioso tabernáculo o presviterio [...] que señorea toda la iglesia: en él se encierra la custodia todo el año con quatro puertas, [...] y quando en alguna festividad se ha de manifestar el Santísimo Sacramento se quitan al tabernáculo las puertas y, corriendo los belos, queda manifiesto a toda la iglesia, pues los fieles le goçan desde cualquier capilla (1987: 63).

Esa centralidad de la eucaristía en la vida de la Iglesia y de cada cristiano, que se hizo arquitectura en la catedral granadina proyectada por Siloe, partía ciertamente del deseo expresado por los Reyes Católicos de que sus restos reposaran ante el Santísimo, pero quedó luego integrada en la más amplia concepción de la tradición espiritual jerónima, que veía 


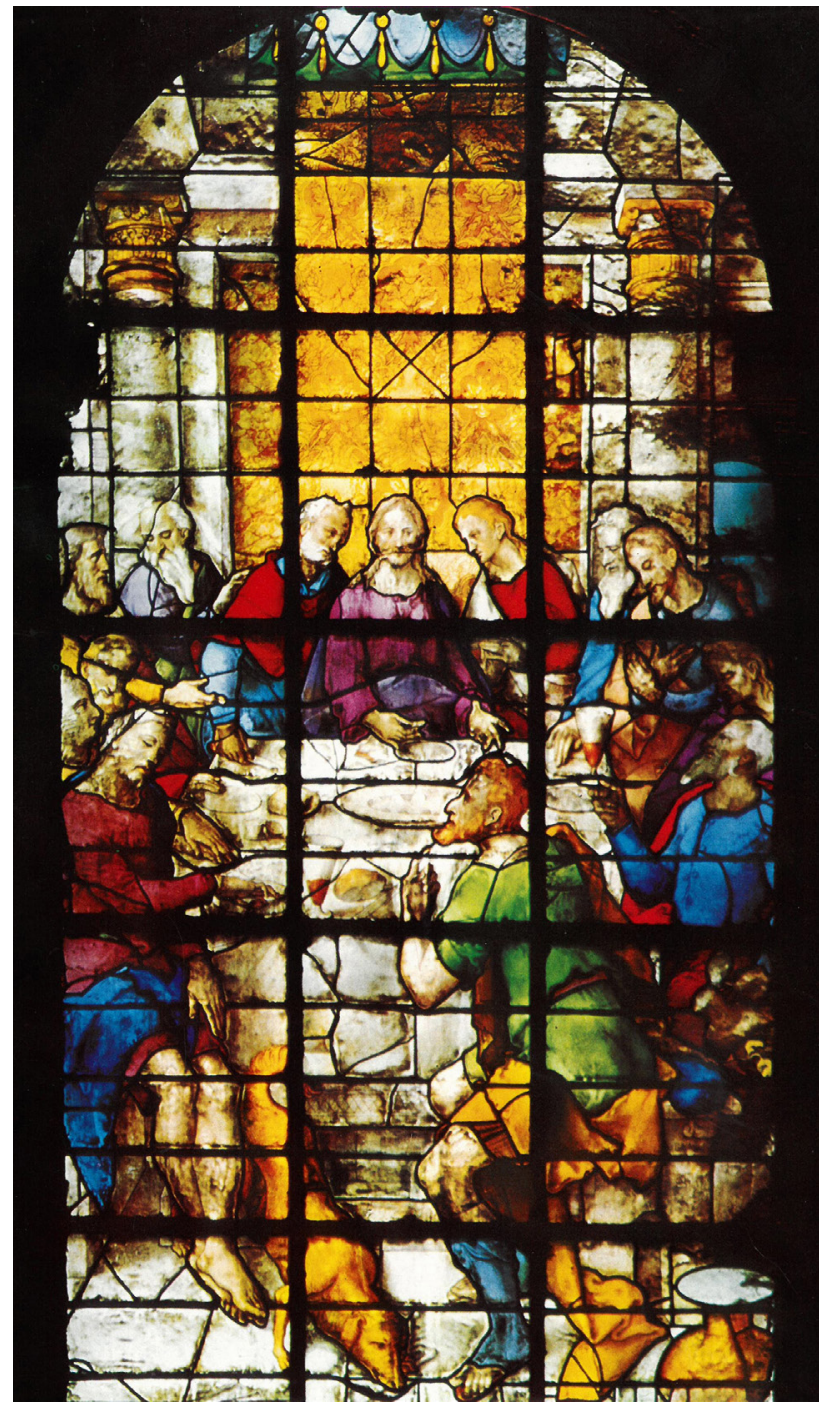

9. Teodoro de Holanda, La última cena (1559). Vidriera de la capilla mayor de la catedral, Granada

en la misa la expresión acabada de la unión de los cristianos con Cristo en un único corpus mysticum, realizada mediante la comunión en el corpus verum. Es, pues, a ese acervo de ideas al que remiten fundamentalmente las formas italianizantes empleadas por Siloe para dar forma a la capilla mayor y que, aunque sean contemporáneas del erasmismo español, deben más a Talavera que a Erasmo, quien sin embargo ha pasado por ser la referencia fundamental para la imagen del cuerpo místico en las primeras décadas del siglo XVI ${ }^{11}$

Ello no es óbice para reconocer que en esos años se produjo una notable convergencia de ideas procedentes de

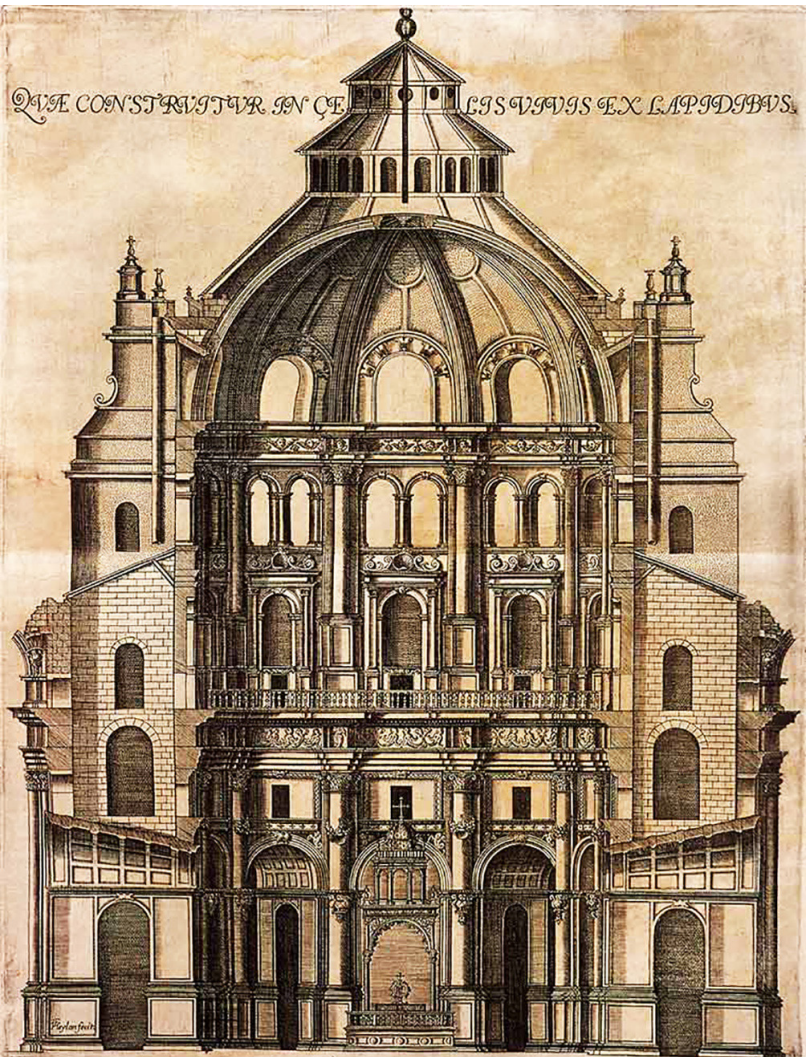

10. Ambrosio de Vico (atribuido), Sección de la capilla mayor de la catedral de Granada. Grabado por Francisco Heylan (1612 ca.)

diversas tradiciones, de la que encontramos un significativo ejemplo en el Diálogo de doctrina christiana, un catecismo anónimo publicado en Alcalá de Henares en 1529, de claro sabor erasmiano, atribuido a Juan de Valdés ${ }^{12}$. El diálogo, situado en Granada, tiene como protagonista al arzobispo Ramiro de Alba, en cuya boca se pone una exposición de lo que era común a los diferentes idearios reformistas de la época. Por lo que a la eucaristía se refiere, el planteamiento del Diálogo no es muy diferente al de Talavera. De hecho, en él se afirma con toda claridad que «la intención con que la Iglesia [... nos manda que oigamos la misa [es] para que entendamos los misterios que allí se representan» (Valdés, 1979: 93). En esto venían a coincidir la tradición jerónima y la erasmista, pues ambas veían en la consagración del pan y el vino una «representación» no solo del corpus verum de Cristo, sino también de su corpus mysticum, adelantándose así a la eclesiología eucarística contemporánea. 


\section{Notas}

1 Anteriormente era la expresión corpus mysticum la que designaba la eucaristía; la historia de esa inversión terminológica se puede ver en De Lubac, 1944.

2 No en vano el Lumen estaba en la biblioteca de Talavera (Aldea, 1976: 532).

3 Breve suma de la santa vida de fray Hernando de Talavera, la copió y ordenó el lic. Gerónimo de Madrid, Biblioteca Nacional de España, Madrid, ms. 9545, fol. $14 \mathrm{r}$.

4 De hecho, las primeras biografías del arzobispo fueron escritas inmediatamente: una primera atribuida a Jerónimo de Madrid y otra, más elaborada, redactada por Alonso Fernández de Madrid.

5 El contrato de Siloe se puede ver en Gómez-Moreno, 1941: 181-182.

6 «Primeramente mandamos que en la yglesia cathedral de Nuestra Señora Sancta María de la O, de la ciudad de Granada, se faga una honorada capilla a la mano derecha de la capilla mayor de la dicha yglesia, en la qual [...] sean nuestros cuerpos sepultados, la qual dicha capilla se ha de llamar de los Reyes [...] y ha de estar en la dicha nuestra capilla el Sacramento de la yglesia mayor» (Real Cédula, de 13 de septiembre de 1504, de erección de la Capilla Real de Granada, en Pita Andrade (ed.), 1994: 300). La referencia a San Isidoro de León en Rosenthal, 1990: 159.

7 Tal vez por eso ha sido descrita como «un templo en forma de cuerpo humano, cuya cabeza es la capilla mayor en forma circular» (Bermúdez de Pedraza, 1981: fol. 80r).

8 Las palabras entre paréntesis remiten a los motivos de las vidrieras de la rotonda.

9 La realización y colocación de las vidrieras se llevó a cabo, bajo la dirección de Siloe, entre 1554 y 1561. Si no fue Alba el mentor de ese programa iconográfico -había fallecido en 1528-, bien pudo serlo su sucesor Gaspar Dávalos, que fue el verdadero ejecutor de muchos de los proyectos talaverianos.

10 Esa posibilidad fue planteada por Rosenthal, 1990: 142-150, que trató de enmarcarla dentro de la "ola erasmista» de la España de comienzos del siglo XVI, ya estudiada en Bataillon, 1950.

11 Para los antecedentes españoles de esa imagen véase Maravall, 1983; de particular interés para nuestro caso lo señalado en Sicroff, 1981: $328-329$.

12 Un ejemplar del Diálogo fue encontrado y publicado en los años veinte por Bataillon, quien lo atribuyó a Juan de Valdés; recientemente, en un documentado estudio Francisco Calero y Marco Antonio Coronel han propuesto como autor a Luis Vives. En todo caso, es claro que quienquiera que fuera su autor tuvo como referencia el diálogo erasmiano Inquisitio de fide (1524).

\section{Bibliografía}

ALDEA, Quintín (1976), «Hernando de Talavera, su testamento y su biblioteca», en Homenaje a Fray Justo Pérez de Urbel, vol. 1, Abadía de Santo Domingo, Silos, pp. 513-547.

BATAILLON, Marcel (1950), Erasmo y España. Estudios sobre la historia espiritual del siglo XVI, 2 vols., Fondo de Cultura Económica, México. BERMÚDEZ DE PEDRAZA, Francisco (1981), Antigüedad y excelencias de Granada, facsímil de la edición de 1608, Colegio de Arquitectos de Andalucía Oriental, Granada.

BUSTAMANTE, Agustín y MARÍAS, Fernando (1982), «La catedral de Granada y la introducción de la cúpula en la España del Renacimiento», Boletín del Museo e Instituto Camón Aznar, n. ${ }^{\circ}$ 8, pp. 103-115.

DE LUBAC, Henri (1944), Corpus mysticum: l'eucharistie et l'Église au Moyen Âge. Étude historique, Aubier, París.

FOLGADO GARCÍA, Jesús (2014): «Las lenguas romances y la evangelización granadina. La aportación de Hernando de Talavera y la liturgia en arábigo de Pedro de Alcalá», Espacio, Tiempo, Forma, n. ${ }^{\circ}$ 27, pp. 229-238.

GÓMEZ-MORENO, Manuel (1941), Las águilas del Renacimiento español. Bartolomé Ordóñez, Diego Siloe, Pedro Machuca, Alonso Berruguete. 1517-1558, CSIC, Madrid.

- (1963), Diego Siloe. Homenaje en el IV centenario de su muerte, Universidad de Granada, Granada.

HENRÍQUEZ DE JORQUERA, Francisco (1987), Anales de Granada, vol. 1, Universidad de Granada, Granada.

KANTOROWICZ, Ernst (1985), Los dos cuerpos del rey. Un estudio de teología política medieval, Alianza, Madrid.

LÓPEZ GUZMÁN, Rafael (2000), «El grabado de la capilla mayor de la catedral de Granada», en MARTíNEZ MEDINA, Francisco Javier (ed.): Jesucristo y el emperador cristiano, Cajasur, Córdoba, pp. 129-131.

MARAVALL, José Antonio (1983): «La idea de cuerpo místico en España antes de Erasmo», en Estudios de historia del pensamiento español, vol. 1, Cultura Hispánica, Madrid, pp. 179-199.

MARÍAS, Fernando (1988), «De iglesia a templo: notas sobre la arquitectura religiosa del siglo XVl», en ROSENTHAL, Earl et al., Seminario sobre arquitectura imperial, Universidad de Granada, Granada, pp. 113-135.

- (1989), El largo siglo XVI. Los usos artísticos del Renacimiento español, Taurus, Madrid. 
NIETO ALCAIDE, Víctor (1973), Las vidrieras de la catedral de Granada, Universidad de Granada, Granada.

OROPESA, Alonso de (1979), Luz para conocimiento de los gentiles, Universidad Pontificia de Salamanca \& FUE, Madrid.

PASTORE, Stefania (2010), Una herejía española. Conversos, alumbrados e Inquisición (1449-1559), Marcial Pons, Madrid.

PEINADO GUZMÁN, José Antonio (2010), «El tabernáculo de la catedral de Granada: de Diego de Siloe a Navas Parejo», Cuadernos de Arte, n. ${ }^{\circ} 41$, pp. 43-62.

PITA ANDRADE, José Manuel (ed.) (1994), El libro de la Capilla Real, Miguel Sánchez, Granada.

ROSENTHAL, Earl (1990), La catedral de Granada. Un estudio sobre el Renacimiento español, Universidad de Granada, Granada.

- (2005), «Del proyecto gótico de Egas al modelo renacentista de Siloe», en GILA MEDINA, Lázaro (coord.), El libro de la catedral de Granada, Cabildo Metropolitano, Granada, vol. I, pp. 93-127.

SICROFF, Albert (1981), «Anticipaciones del erasmismo español en el Lumen ad revelationem gentium de Alonso de Oropesa», Nueva Revista de Filología Hispánica, vol. 30, n. ํ 2, pp. 315-333.

TOAJAS, María Ángeles (2007), «Artistas hispanos en Italia en el siglo XVI: los viajes de Diego Siloe y Pedro Machuca», en CHECA, Fernando y GONZÁLEZ GARCÍA, José Luis (coords.), El viaje del artista en la Edad Moderna. Materiales para su estudio, Universidad Complutense, Madrid, pp. 1-21.

TALAVERA, Hernando de (1911), Tractado de lo que significan las cerimonias de la misa, en MIR, Miguel (ed.), Escritores místicos españoles, vol. 1, Bailly-Baillière, Madrid, pp. 79-93.

- (2014), Dos escritos destinados a la reina Isabel, Universitat de València, Valencia.

VALDÉS, Juan de (1979), Diálogo de doctrina christiana, Editora Nacional, Madrid.

VON SIMSON, Otto (1980), La catedral gótica, Alianza, Madrid. 